\title{
Assessing ENSO Summer Teleconnections, Impacts, and Predictability in North America
}

\author{
Bor-Ting Jong, ${ }^{\mathrm{a}}$ Mingfang Ting, ${ }^{\mathrm{b}}$ And Richard SEAGER ${ }^{\mathrm{b}}$ \\ ${ }^{\text {a } N O A A / P h y s i c a l ~ S c i e n c e s ~ L a b o r a t o r y, ~ B o u l d e r, ~ C o l o r a d o ~}$ \\ ${ }^{\mathrm{b}}$ Lamont-Doherty Earth Observatory, Columbia University, Palisades, New York
}

(Manuscript received 29 September 2020, in final form 22 January 2021)

\begin{abstract}
During the summer when an El Niño event is transitioning to a La Niña event, the extratropical teleconnections exert robust warming anomalies over the U.S. Midwest threatening agricultural production. This study assesses the performance of current climate models in capturing the prominent observed extratropical responses over North America during the transitioning La Niña summer, based on atmospheric general circulation model experiments and coupled models from the North American Multimodel Ensemble (NMME). The ensemble mean of the SST-forced experiments across the transitioning La Niña summers does not capture the robust warming in the Midwest. The SST-forced experiments do not produce consistent subtropical western Pacific (WP) negative precipitation anomalies and this leads to the poor simulations of extratropical teleconnections over North America. In the NMME models, with active air-sea interaction, the negative WP precipitation anomalies show better agreement across the models and with observations. However, the downstream wave train pattern and the resulting extratropical responses over North America exhibit large disagreement across the models and are consistently weaker than in observations. Furthermore, in these climate models, an anomalous anticyclone does not robustly translate into a warm anomaly over the Midwest, in disagreement with observations. This work suggests that, during the El Niño to La Niña transitioning summer, active air-sea interaction is important in simulating tropical precipitation over the WP. Nevertheless, skillful representations of the Rossby wave propagation and land-atmosphere processes in climate models are also essential for skillful simulations of extratropical responses over North America.
\end{abstract}

KEYWORDS: ENSO; Teleconnections; Climate prediction; Seasonal forecasting; Model evaluation/performance; North America

\section{Introduction}

Current climate models have not yet shown much skill in predicting Northern Hemisphere extratropical atmospheric circulations and hydroclimate variability over North America during the boreal summer season (e.g., Wang et al. 2009; Ding et al. 2011; Merrifield and Xie 2016; Chang et al. 2019; Malloy and Kirtman 2020), in stark contrast to the boreal winter season. Yet, El Niño-Southern Oscillation (ENSO), the primary source of predictability on seasonal time scales, influences North American hydroclimate in the summer, such as the interannual variability of the Great Plains low-level jet (e.g., Weaver and Nigam 2008; Liang et al. 2015), Great Plains precipitation (e.g., Ting and Wang 1997), and Midwest surface temperature (e.g., Lau et al. 2005; Wang et al. 2007; Jong et al. 2020). These meteorological responses to ENSO can significantly impact flooding hazard (e.g., Yan et al. 2020) and crop yields during the summer growing season (e.g., Anderson et al. 2017a) in the central United States, a primary global agricultural production area. Because of the broad socioeconomic consequences, ENSO summer teleconnections and their impacts on North America in state-of-the-art climate models are worth examining further. This study aims to advance our understanding of the simulation and prediction of ENSO summer teleconnections over North America in various SST-forced and operational seasonal prediction models.

A typical ENSO event develops in early boreal summer, peaks at the end of the calendar year and weakens in the

Corresponding author: Bor-Ting Jong, bor-ting.jong@noaa.gov subsequent spring to summer (e.g., Rasmusson and Carpenter 1982; Larkin and Harrison 2002). During an ENSO event, anomalous tropical deep convection, induced by sea surface temperature (SST) anomalies, can trigger upper-level Rossby wave propagation from the tropics, across the North Pacific, and to extratropical North America (e.g., Hoskins and Karoly 1981), with the aid of the subtropical jet stream as a waveguide (e.g., Hoskins and Ambrizzi 1993; Ting and Sardeshmukh 1993). In the summer, although the subtropical jet stream is weaker and shifted poleward compared to that in the winter, the subtropical jet stream establishes a strong meridional vorticity gradient with nearly circumglobal extent, providing an important pathway for Rossby wave propagation (e.g., Ambrizzi et al. 1995; Newman and Sardeshmukh 1998; Branstator 2002; Ding and Wang 2005; Schubert et al. 2011; Teng et al. 2013; Wang et al. 2017; O'Reilly et al. 2018). Consequently, ENSO tropical forcing, albeit weaker during the developing and decaying ENSO phases, is able to activate Rossby wave propagation toward higher latitudes and modulate the U.S. summertime climate (e.g., Liu et al. 1998; Lau et al. 2005; Ding et al. 2011; Jong et al. 2020).

The characteristics of ENSO in the summer are strongly linked to the evolution of oceanic conditions from the preceding winter, due to the complexity of the multiyear evolution of ENSO (e.g., Anderson et al. 2017b; Yu and Fang 2018; Jong et al. 2020). For example, La Niña tends to transition from El Niño and persist through the summer and often reintensify in the following winter becoming a multiyear La Niña event (e.g., McPhaden and Zhang 2009; Hu et al. 2014; Okumura 2019; Wu et al. 2019; Fang and Yu 2020). The summer when an El Niño event is transitioning to a La Niña event (transitioning La Niña 



FIG. 1. Composites of (a),(c) precipitation anomalies (shaded; $\mathrm{mm} \mathrm{day}^{-1}$ ) and 200-hPa geopotential height anomalies with the zonal mean removed (contours; interval: $5 \mathrm{~m}$ ) and (b), (d) detrended surface temperature (Ts) for the transitioning La Niña summers from (a),(b) NCEP-NCAR R1 during 1950-2018 and (c),(d) ERA-Interim during 1979-2018. Stippling denotes the $90 \%$ confidence for precipitation and Ts anomalies using a two-tailed Student's $t$ test. Thick lines indicate the $90 \%$ confidence for 200 -hPa height variations. Purple boxes indicate the WP $\left(5^{\circ}-25^{\circ} \mathrm{N}, 110^{\circ}-170^{\circ} \mathrm{E}\right)$, eastern North America $\left[30^{\circ}-60^{\circ} \mathrm{N}, 110^{\circ}-70^{\circ} \mathrm{W}\right.$ in (a) $]$, and Midwest $\left[36^{\circ}-49^{\circ} \mathrm{N}, 103^{\circ}-82^{\circ} \mathrm{W}\right.$ in (b)] regions used in Figs. 3 and 5.

summer), and the summer when La Niña is persisting from one to the next (persisting La Niña summer), were both loosely defined as "La Niña" summers in the majority of previous studies, despite the different evolutions of tropical SST and the resulting differences in North American teleconnections (Jong et al. 2020). During the transitioning La Niña summer, the tropical central to eastern Pacific has rapidly turned into the $\mathrm{La}$ Niña state, while the El Niño-induced warming lingers around from the Indian Ocean to the tropical western Pacific (e.g., Wang et al. 2001; Lau et al. 2005; Xie et al. 2009, 2016). On the other hand, during the persisting La Niña summer, the La Niña-induced cooling extends from the Indian Ocean across the entire tropical Pacific, leading to a distinct distribution of SST anomalies across the tropics from the transitioning $\mathrm{La}$ Niña summer (Jong et al. 2020).

The distinct oceanic characteristics lead to different atmospheric responses over the tropical Pacific and extratropical North America during these two types of La Niña summers (Livneh and Hoerling 2016; Jong et al. 2020). For the transitioning La Niña summer, the developing La Niña negative SST anomalies induces suppressed deep convection over the tropical central Pacific (CP) (Figs. 1a,c). At the same time, the Indian Ocean warming, caused by the decaying El Niño, drives enhanced deep convection and triggers baroclinic Kelvin waves extending into the western Pacific (WP), causing upper troposphere warming and low-level divergence and thereby suppressing deep convection over the subtropical WP (e.g., Wang et al. 2001; Xie et al. 2009, 2016; Zhou et al. 2018). It has been well known that convective heating anomalies over the subtropical WP can trigger Rossby waves that propagate downstream to North America during the boreal summer (e.g., Lau et al. 2005; Ding et al. 2011; Zhu and Li 2016; Lopez et al. 2019; Jong et al. 2020). Therefore, over
North America this Rossby wave superimposes on the Rossby wave triggered by the suppressed convection over the tropical $\mathrm{CP}$, leading to statistically significant extratropical teleconnections. The teleconnections impose an anomalous anticyclone over northeastern North America and subsequently a robust warming over the Midwest (Figs. 1b,d). This prominent warm anomaly over the Midwest is unique to the transitioning La Niña summer. These tropical and extratropical responses during the transitioning La Niña summer are robust across multiple reanalysis datasets, including National Centers for Environmental Prediction-National Center for Atmospheric Research Reanalysis 1 (NCEPNCAR R1; Kalnay et al. 1996) from 1950 to 2018 (Figs. 1a,b), European Centre for Medium-Range Weather Forecasts interim reanalysis dataset (ERA-Interim; Dee et al. 2011) from 1979 to 2018 (Figs. 1c,d), and Japanese 55-year Reanalysis (JRA-55; Kobayashi et al. 2015) from 1958 to 2018 (not shown). During the persisting La Niña summer, only the suppressed deep convection over the tropical CP induced by the La Niña SST forcing is present, insufficient to impose statistically significant impacts on the United States (Jong et al. 2020).

The physical processes explaining the Midwest warming during the transitioning La Niña summer and the distinct impacts on the United States between the transitioning and persisting La Niña summers are documented in Jong et al. (2020), based on observational data and idealized stationary wave model experiments. The warming over the Midwest and its impacts on crop yields underscore the importance of determining to what extent current climate models are able to capture ENSO summer teleconnections in both the tropics and extratropics. Therefore, in this study, we further assess the ability of climate models to simulate the ENSO responses 
during the transitioning La Niña summer which leads to robust warming anomalies over the Midwest. We will evaluate three aspects following the physical processes described above and in Jong et al. (2020) for the transitioning La Niña summer in stateof-the-art climate models:

1) Can climate models generate the ENSO tropical forcing over the tropical central Pacific and subtropical western Pacific?

2) Can Rossby waves triggered by ENSO tropical forcing propagate cross the Pacific-North American (PNA) region?

3) If models are able to simulate the anomalous anticyclone in North America, can models realistically capture the strong and robust surface warming?

The assessments are built on two sets of modeling analyses: 1) atmospheric general circulation model (AGCM) experiments with observed SST prescribed, for which we use the National Center for Atmospheric Research (NCAR) Community Atmospheric Model, version 5 (CAM5), and 2) the North American Multimodel Ensemble (NMME) operational forecasting models, which are fully coupled ocean-atmosphere models initialized from observed SST and atmospheric conditions (Kirtman et al. 2014). The rest of the paper is organized as follows. In section 2, we detail the observational data and the various models used. In section 3, we assess the ability of NCAR-CAM5 AGCM experiments to simulate the ENSO responses during the transitioning La Niña summers. Section 4 evaluates the skill of NMME models in simulating the ENSO summer teleconnections. Conclusions and discussions are provided in section 5 .

\section{Data and method}

\section{a. Observed data}

NCEP-NCAR R1 (Kalnay et al. 1996) is used as the reference to assess the climate models in this study. This dataset provides monthly variables on a $2.5^{\circ} \times 2.5^{\circ}$ latitude-longitude grid for pressure-level data and a T64 Gaussian grid for surface data, spanning from 1948 to the present. The observed ENSO responses, including tropical precipitation, 200-hPa geopotential height, and surface temperature, are also verified with the ERA-Interim which provides monthly variables from 1979 to the present with spatial resolution of $1.5^{\circ} \times 1.5^{\circ}$ (Dee et al. 2011).

\section{b. $A G C M$}

The AGCM used in this study is the NCAR-CAM5 with T42 horizonal resolution and 30 vertical levels (Neale et al. 2012). We use output from 16-member Global Ocean and Global Atmosphere (GOGA) simulations where observed monthly historical SST and sea ice from the Hadley Centre Sea Ice and Sea Surface Temperature, version 2 (Titchner and Rayner 2014) are prescribed over the global oceans for the period 1856 to 2019 (Guo et al. 2017; Lee et al. 2018). The NCAR CAM5GOGA experiment is coupled with the Community Land Model version 4 (CLM4). To be consistent, for both NCEP-
NCAR R1 and CAM5-GOGA, the 3-month climatology is based on the period 1950-2018.

\section{c. NMME seasonal forecast data}

Besides the AGCM, we also assess the characteristics of ENSO summer teleconnections in coupled climate models derived from NMME. NMME is an experimental multimodel seasonal forecasting system (Kirtman et al. 2014). Seven coupled climate models from the NMME are used in this research:

- NCAR Community Climate System Model, version 4 (CCSM4; Danabasoglu et al. 2012)

- Geophysical Fluid Dynamics Laboratory, Global Climate Model, version 2.1 (GFDL-CM2.1; Delworth et al. 2006)

- GFDL Forecast-oriented Low Ocean Resolution version of CM2.5 (GFDL-FLOR; Vecchi et al. 2014)

- National Aeronautics and Space Administration, Goddard Earth Observing System model, version 5 (NASA-GEOS5; Vernieres et al. 2012)

- Third and Fourth Generation Canadian Coupled Global Climate Model (CanCM3 and CanCM4, respectively; Merryfield et al. 2013)

- NCEP Climate Forecast System, version 2 (NCEP-CFSv2; Saha et al. 2006, 2014)

The number of ensemble members are 10 (for CCSM4, CanCM3, and CanCM4), 12 (for GFDL-CM2.1, GFDLFLOR, and NASA-GEOS5), and 24 (for NCEP-CFSv2).

All the models provide hindcasts from 1981 to 2010 and realtime forecasts starting from 2011, with a consistent spatial resolution of $1^{\circ} \times 1^{\circ}$. In this study, we use June-July-August (JJA) 3-month-average forecast initialized with 1 June atmospheric and oceanic conditions. The NMME data are accessible at the International Research Institute for Climate and Society, Columbia University, Data Library (http://iridl.ldeo. columbia.edu/SOURCES/.Models/.NMME/).

For both the observations and model outputs, the SST, surface temperature over land area, and surface heat fluxes are linearly detrended using JJA seasonal means.

\section{d. Definition of transitioning La Niña summers}

As in Jong et al. (2020), a transitioning La Niña summer is selected when the preceding winter is defined as an El Niño event and the succeeding winter is defined as a La Niña event. We define El Niño and La Niña winters based on the Oceanic Niño Index (ONI) published on the NOAA Climate Prediction Center (CPC) website [https://origin.cpc.ncep.noaa. gov/products/analysis_monitoring/ensostuff/ONI_v5.php]. The ONI is a 3-month running mean of SST anomalies in the Niño3.4 region $\left(5^{\circ} \mathrm{N}-5^{\circ} \mathrm{S}, 170^{\circ}-120^{\circ} \mathrm{W}\right)$, relative to a 30 -yr climatology. The 30 -yr base period is updated every 5 years and centered at the first year of these 5 years (e.g., for 1950-54, the $30-y r$ climatology is based on 1936-65; for 1956-60, the 30-yr climatology is based on 1941-70. See the aforementioned CPC ONI website for detailed information). The El Niño and La Niña events are defined when the ONI reaches the threshold of $+0.5^{\circ}$ and $-0.5^{\circ} \mathrm{C}$, respectively, for a minimum of 5 consecutive overlapping 3-month averages. There are 12 transitioning La Niña summers identified during 1950 to 2018 in 

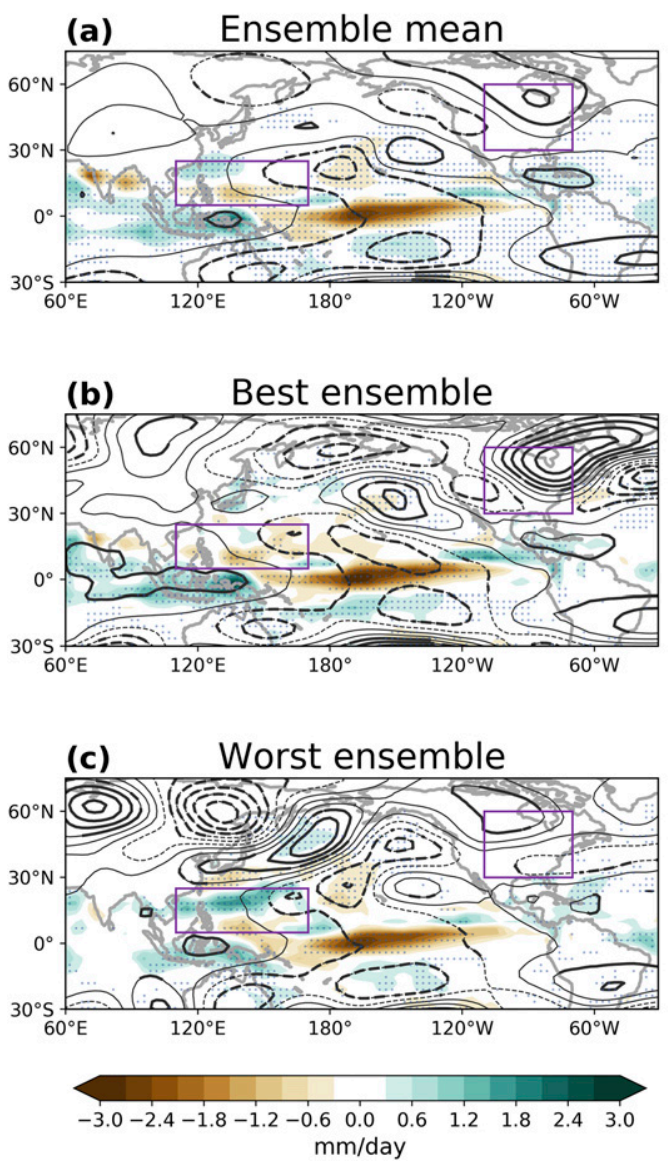
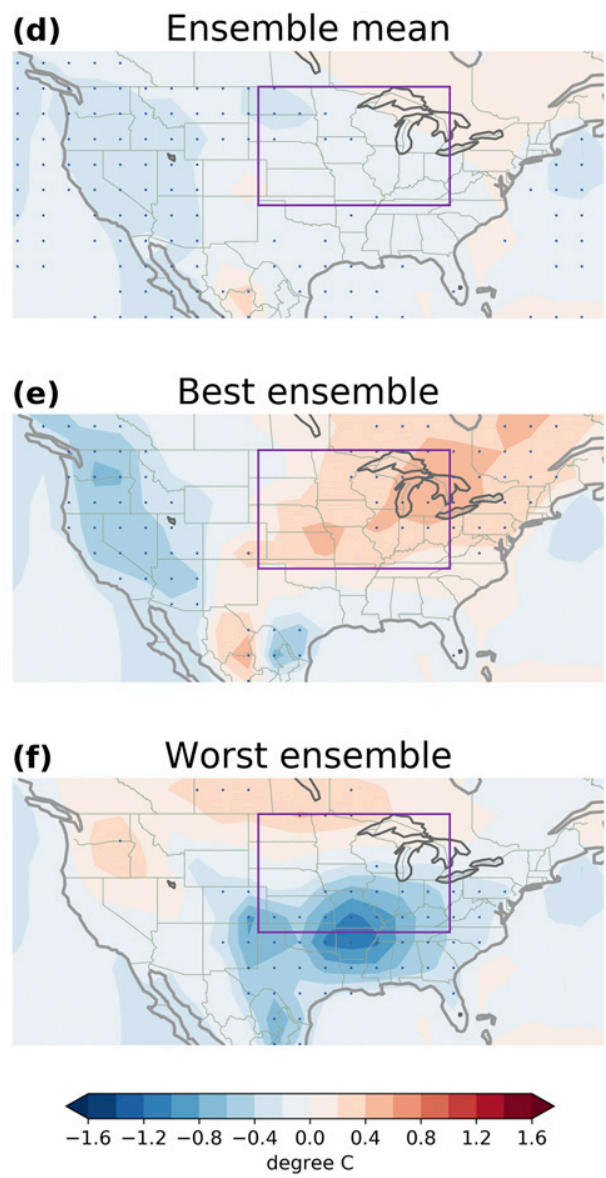

FIG. 2. Composites of (a)-(c) precipitation anomalies (shaded; $\mathrm{mm} \mathrm{day}^{-1}$ ) and 200-hPa geopotential height anomalies with the zonal mean removed (contours; interval: $5 \mathrm{~m}$ ) and (d)-(f) detrended Ts from CAM5-GOGA for the transitioning La Niña summers during 1950-2018. For (a) and (d), the composites are based on the CAM5GOGA ensemble mean. For (b), (c), (e), and (f), the composites are constructed by the ensemble member whose $\mathrm{Z} 200$ has (b),(e) the highest and (c),(f) the lowest pattern correlation with NCEP-NCAR R1 over the PNA region for each transitioning La Niña summer. Stippling denotes the $90 \%$ confidence for precipitation and Ts anomalies using a two-tailed Student's $t$ test. Thick lines indicate the $90 \%$ confidence for 200 -hPa height variations. Purple boxes indicate the regions used in Figs. 3 and 5.

this study: 1954, 1964, 1970, 1973, 1983, 1988, 1995, 1998, 2005, 2007, 2010, and 2016. We focus on the season of JJA throughout the study.

\section{SST-forced responses in CAM5-GOGA}

\section{a. Composites of tropical and extratropical responses in CAM5-GOGA}

First, the CAM5-GOGA ensemble mean is examined to evaluate the SST-forced responses during the transitioning La Niña summers in the model. Figures $2 \mathrm{a}$ and $2 \mathrm{~d}$ show the ensemble mean composites for the 12 transitioning La Niña summers for precipitation, 200-hPa geopotential height, and the U.S. surface temperature (Ts). In the tropics, the suppressed deep convection (negative precipitation anomalies) over the tropical CP induced by the developing La Niña cold SST anomalies is well represented in the model ensemble mean (cf. Fig. 2a to Fig. 1a). The enhanced precipitation over the tropical Indian Ocean to the Maritime Continent, induced by the warm SST anomalies triggered by the decaying El Niño, is also well reproduced by the ensemble mean. However, the suppressed deep convection over the subtropical WP, also related to the decaying El Niño (Xie et al. 2009; Jong et al. 2020), is much weaker and less extensive in the ensemble mean as compared to the observations (Fig. 1a). The tropical circulations in the model ensemble mean share basic features with the observations, including a pair of anomalous cyclones located poleward of the anomalous equatorial diabatic cooling and the anomalous anticyclone over the Maritime Continent with comparable intensities.

The extratropical responses in the CAM5-GOGA ensemble mean during the transitioning La Niña summer (Figs. 2a,d), on the other hand, are much weaker than the corresponding observations (Fig. 1). The anomalous cyclone located near the 
Gulf of Alaska and the anomalous anticyclone over northeastern North America are much weaker in the CAM5-GOGA ensemble mean than in NCEP-NCAR R1. The discrepancy in the anomalous extratropical circulations is also reflected in the surface temperature over the United States (cf. Fig. 2d to Fig. 1b): only weak warm anomalies are present in the northeastern United States in the model ensemble mean, unlike in the observations where statistically significant warm anomalies cover most of the area east of the Rocky Mountains. The poor simulation of the extratropical responses indicate that the model's SST-forced responses are not enough to explain the observed patterns during the transitioning La Niña summer.

To evaluate if the model has the ability to correctly represent the observed La Niña summer teleconnections, we construct a new La Niña composite: for each transitioning La Niña summer, we select the ensemble member that has the highest pattern correlation for the $200-\mathrm{hPa}$ geopotential height anomalies over the PNA region $\left(0^{\circ}-60^{\circ} \mathrm{N}, 120^{\circ} \mathrm{E}-60^{\circ} \mathrm{W}\right.$, PNA Z200 hereafter $)$ for that event. We then composite across the selected ensemble members and call it the "best ensemble composite" (Figs. 2b,e). The composite of anomalous circulations based on the best ensemble members is much closer to the NCEP-NCAR R1 (Fig. 2b, pattern correlation for the PNA Z200 with NCEPNCAR R1 is 0.77), compared to the one based on all ensemble members (Fig. 2a, pattern correlation for the PNA Z200 is 0.59). Specifically, in the best ensemble composite, the extratropical teleconnections extend from the North Pacific to North America region and the anomalous anticyclone over northeastern North America is stronger and more distinct (Fig. 2b), leading to a stronger and southward-expanded warming signal over the Midwest (Fig. 2e). This result indicates that the model forced with the historical SST is able to simulate an extratropical circulation pattern similar to that in observations in the transitioning La Niña summer. We similarly constructed the worst ensemble composite (Figs. 2c,f), based on the worst ensemble member of each transitioning La Niña summer according to the lowest pattern correlation in the PNA Z200 between the model and the observations. In this case, there is no clear wave propagation from the tropical Pacific to the North American region (Fig. 2c) and the anomalous U.S. surface temperature is of opposite sign to the observations (Fig. 2f).

The weak extratropical responses in the CAM5-GOGA ensemble mean, therefore, infer two possibilities: 1) The SSTforced responses are indeed very weak and the strong extratropical responses in observations are likely caused by atmospheric internal variability or other physical processes. 2) The SSTforced responses in CAM5-GOGA are incorrectly represented. To address this discrepancy, we further examine how the model simulates the three crucial components that link the La Niña tropical SST anomalies to the U.S. surface temperature responses: tropical precipitation, teleconnection patterns triggered by the tropical forcing, and the extratropical surface responses due to the teleconnections.

\section{b. Processes that connect tropical forcing and extratropical responses}

During the transitioning La Niña summer, two suppressed convection areas are present over the tropical Pacific and both contribute to the extratropical teleconnections (Fig. 1a). As the suppressed convection over the tropical CP is well represented in the model ensemble mean (Fig. 2a), we focus on the suppressed convection over the subtropical WP. This suppressed convection is a robust feature during the transitioning La Niña summers in the observations since 1950: 11 out of the 12 (92\%) historical transitioning La Niña summers experienced drierthan-normal precipitation in this region (Fig. 3a). However, in the CAM5-GOGA ensemble mean (Fig. 3b, orange dots), the precipitation anomalies over the subtropical WP are only slightly favoring negative over positive (58.4\% vs $41.6 \%)$.

The contribution of the WP suppressed convection is to augment the teleconnections triggered by the suppressed convection over the tropical $\mathrm{CP}$, leading to statistically significant responses in the extratropics (Jong et al. 2020). In the observations (Fig. 3d), the negative WP precipitation anomalies are closely associated with anomalous anticyclonic conditions over eastern North America (E-NA). Among the 12 historical transitioning La Niña summers, 8 follow this relationship (located in the lower-right quadrant in Fig. 3d). In CAM5-GOGA, the anomalous anticyclone over E-NA is much weaker in the ensemble mean composite (Fig. 2a), but has similar amplitude in the best ensemble composite (Fig. 2b) as in the observations. Among the 12 best ensemble members (one for each event), 8 follow the negative WP precipitationpositive E-NA Z200 relationship (Fig. 3e, green diamonds) seen in the observations. Since the best ensemble member for each event is selected based on the pattern correlation of Z200 over the PNA region between the observations and the model simulations, the relationship shown in Fig. 3e suggests that a good simulation of the anomalous anticyclone over E-NA tends to be linked to the correct sign (negative) of the WP precipitation anomalies. On the other hand, among the 12 worst ensemble members for each event: only 4 out of the 12 events have the negative WP precipitation-positive E-NA Z200 relationship (Fig. 3e, blue diamonds). This indicates that the poor simulation of the E-NA Z200 in CAM5-GOGA is likely due to the large spread in WP precipitation in the model compared to the observations.

Although the anomalous extratropical circulations during the transitioning La Niña summer are much weaker and less consistent in CAM5-GOGA, it is worth examining whether a reasonable simulation of extratropical teleconnections leads to robust surface temperature responses in North America in the model. The strong surface warming over the Midwest (Fig. 1b) is a robust feature across all the historical transitioning La Niña summers and has a strong relationship with the anomalous anticyclone over E-NA (Fig. 3g). In other words, the presence of an anomalous anticyclone leads to the surface warming over the Midwest (e.g., Meehl and Tebaldi 2004). On the other hand, in the CAM5-GOGA ensemble mean, though $66.7 \%$ of events have the anomalous anticyclone (Fig. 3h, right-upper and -lower quadrants, orange dots), only $16.7 \%$ of the events show the warming over the Midwest while $50 \%$ actually have cooling. Across all ensemble members, the positive relationship between anomalous Z200 and Ts is weak in CAM5GOGA. The weak relationship between atmospheric circulations and surface temperature may imply that the land-atmosphere 
(a) NCEP-NCAR R1

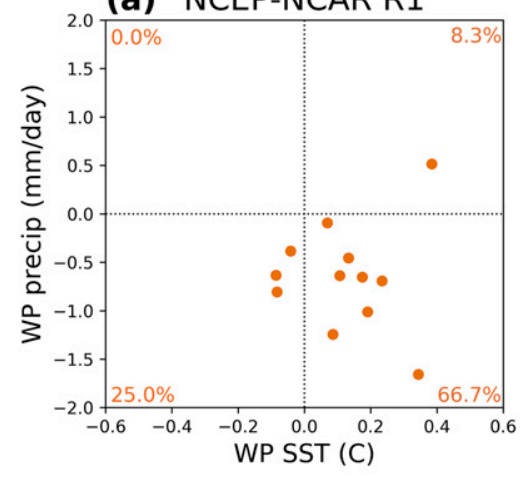

(d) NCEP-NCAR R1

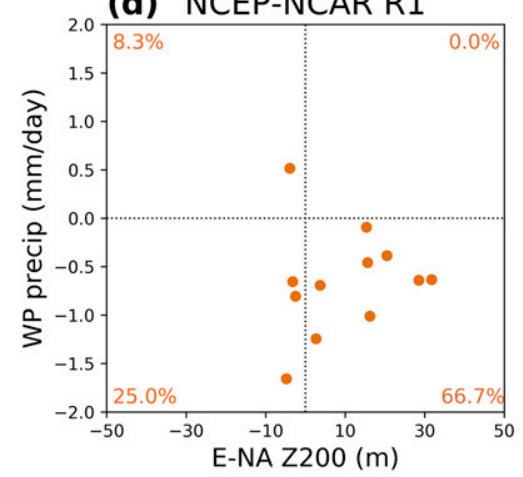

(g) NCEP-NCAR R1

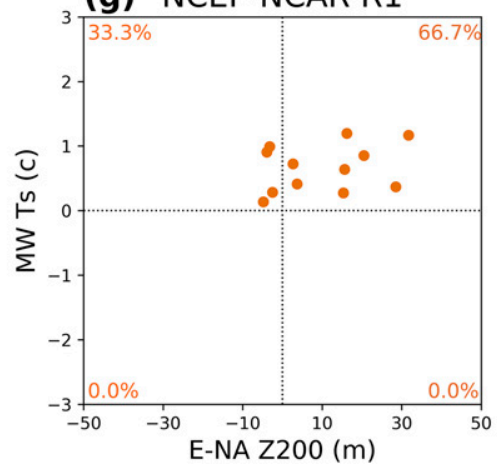

(b) CAM5-GOGA

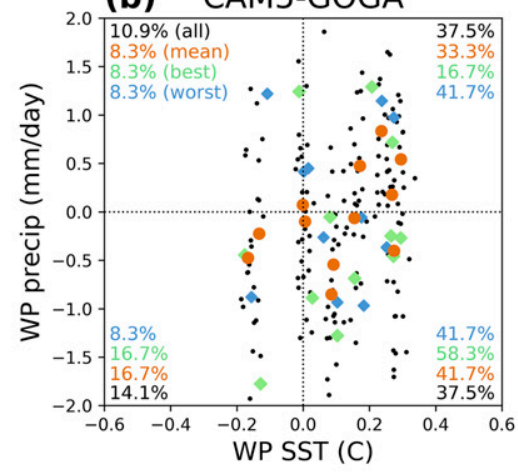

(e) CAM5-GOGA

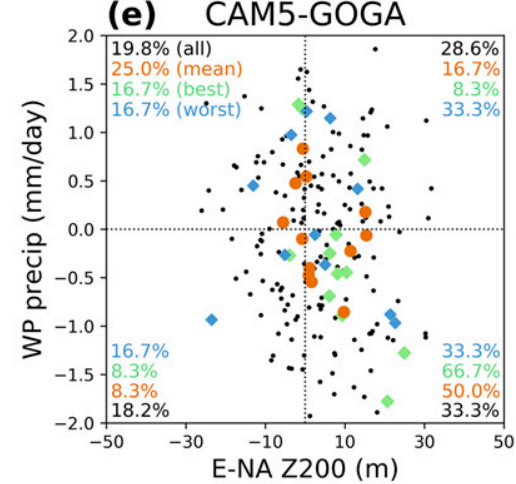

(h) CAM5-GOGA

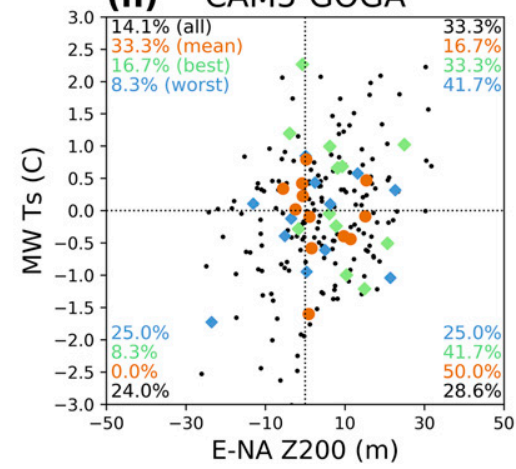

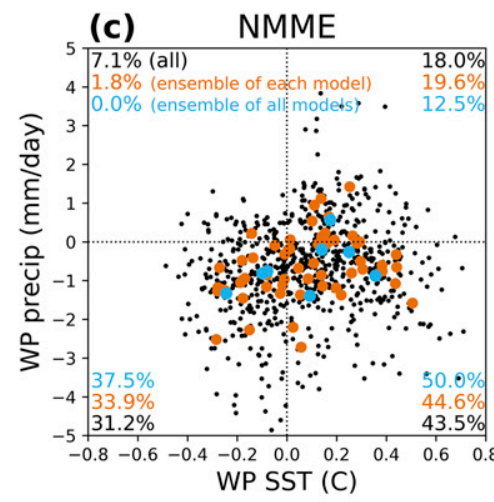
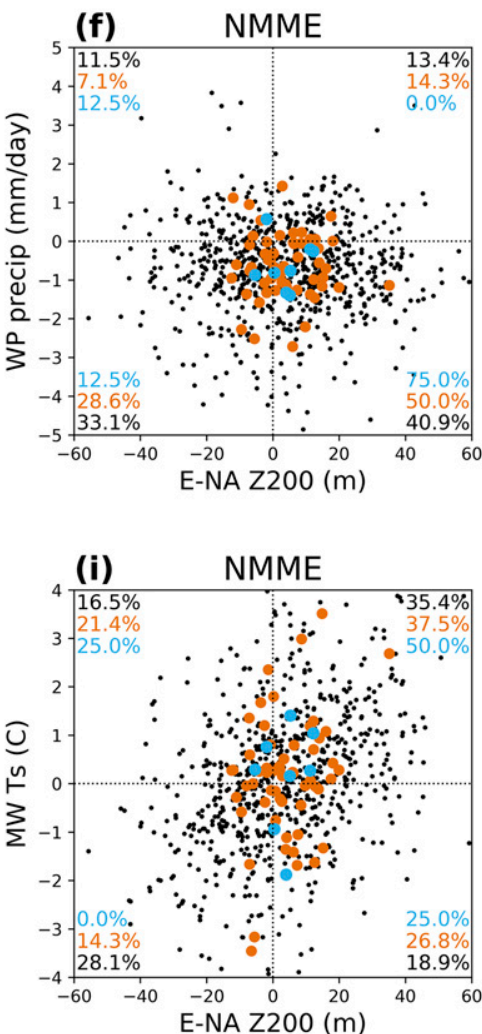

FIG. 3. Scatterplots for (top) precipitation anomalies vs SST anomalies over the subtropical WP $\left(5^{\circ}-25^{\circ} \mathrm{N}, 110^{\circ}-170^{\circ} \mathrm{E}\right)$, (middle) WP precipitation anomalies vs $200-\mathrm{hPa}$ height anomalies over eastern North America (E-NA; $30^{\circ}-60^{\circ} \mathrm{N}, 110^{\circ}-70^{\circ} \mathrm{W}$ ), and (bottom) Midwest (MW; $36^{\circ}-49^{\circ} \mathrm{N}, 103^{\circ}-82^{\circ} \mathrm{W}$ ) Ts anomalies vs E-NA Z200 from (left) NCEP-NCAR R1, (center) CAM5-GOGA, and (right) NMME during the transitioning La Niña summers. The regions of subtropical WP, E-NA, and Midwest are indicated in Figs. 1 and 2. For NCEPNCAR R1 in the left column, each dot indicates each transitioning La Niña summer during 1950-2018. For CAM5-GOGA in the center column, orange (black) dots represent for the ensemble mean (all the ensemble members) from all transitioning La Niña summers during 1950-2018. Green (blue) diamonds are the best (worst) ensemble member for each transitioning La Niña summer. For NMME in the right column, black dots present for all the ensemble members from all transitioning La Niña summers during 1982-2018. Orange dots are the ensemble means of the individual models from all transitioning La Niña summers. Blue dots are the multimodel ensemble mean across seven models for all transitioning La Niña summers. Numbers are the percentages of dots in each quadrant.

interaction in the CAM5 land model is not well represented. We will address this issue later in the Discussion. Regardless, this suggests that even if this model could get the correct extratropical teleconnections, it may still not get the surface warming correctly over North America.
In brief, in the CAM5-GOGA ensemble mean, large variability in the WP precipitation across the transitioning La Niña summers disagrees with the robust observed feature of suppressed convection over the WP. This inconsistency of WP precipitation anomalies may lead to the poor simulations of 
(a)

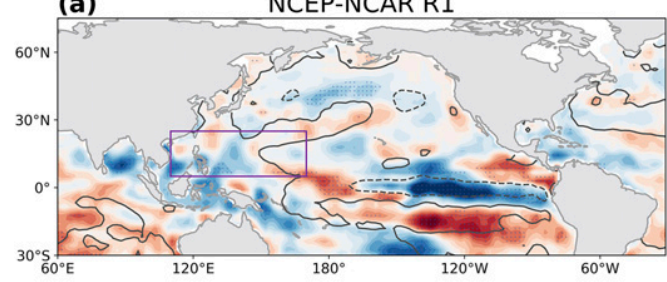

(b) CAM5-GOGA: Ensemble mean

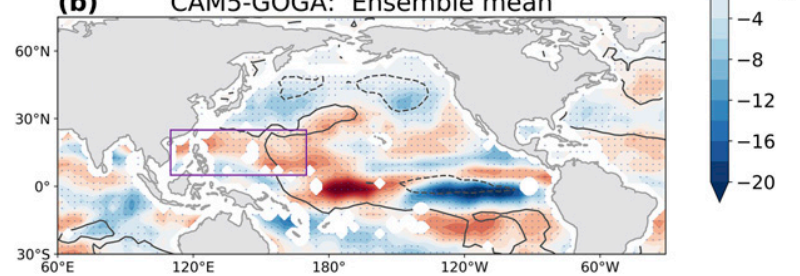

FIG. 4. Composites of SST anomalies (contours) and anomalous upward surface heat fluxes (shaded; latent + sensible heat flux) based on (a) NCEP-NCAR R1 and (b) CAM5-GOGA ensemble mean for the transitioning La Niña summers. For surface heat fluxes, positive values mean the anomalous fluxes are from ocean to atmosphere. For SST anomalies, solid (dashed) lines indicate $+0.5^{\circ} \mathrm{C}\left(-0.5^{\circ} \mathrm{C}\right)$ isotherms. Stippling denotes the $90 \%$ confidence for surface heat fluxes anomalies using a two-tailed Student's $t$ test. Purple boxes indicate the subtropical WP region used in Fig. 5.

anomalous circulations over North America in CAM5-GOGA. In addition, there is an inadequate relationship between anomalous circulations and surface temperature over North America in CAM5-GOGA.

\section{c. Role of air-sea interaction in precipitation over the WP}

As mentioned in the Introduction, the WP suppressed convection is driven by the anomalous anticyclone over the Maritime Continent and the WP (Fig. 1a) which is originally triggered by the warm SST anomalies over the remote Indian Ocean. The mostly negative local SST-precipitation relationship over the WP in observations (Fig. 3a) also implies that the precipitation variability here is not simply driven by the local SST (e.g., Trenberth and Shea 2005; Wu and Kirtman 2007; Zhou et al. 2018). Instead, the warm SST anomalies are responses to the anomalous surface heat fluxes from atmosphere to ocean (Fig. 4a). On the other hand, the prescribed SST setting in CAM5-GOGA does not allow any atmospheric forcing of the ocean. The anomalous surface heat flux in the subtropical WP is instead largely determined by the warm SST anomalies and is from the ocean to the atmosphere (Fig. 4b). Figure 5 shows the time evolutions of the area-averaged precipitation, surface heat flux and SST anomalies over the subtropical WP throughout the ENSO cycle for both NCEPNCAR R1 and the model ensemble mean as well as the best and worst ensemble members defined earlier. Figure 5a shows that suppressed convection in this region starts in the autumn season of the El Niño and persists through the transitioning $\mathrm{La}$ Niña summer in the observations. However, while the ensemble mean from CAM5-GOGA correctly simulates the suppressed convection in the autumn and winter of the El


FIG. 5. Evolutions of 3-month-averaged (a) precipitation anomalies, (b) surface heat flux anomalies, and (c) SST anomalies over the subtropical WP $\left(5^{\circ}-25^{\circ} \mathrm{N}, 110^{\circ}-170^{\circ} \mathrm{E}\right)$. Orange lines are the composites across all the transitioning La Niña events based on NCEP-NCAR R1. For CAM5-GOGA (blue lines), solid, dashed, and dotted lines are the composites constructed from ensemble mean, best ensemble, and worst ensemble, respectively. Gray lines are the composites based on each ensemble member. Red dotted lines indicated with JJA-T are the transitioning La Niña summer that this study focuses on.

Niño, it fails to simulate the suppressed convection in the transitioning La Niña summer. Comparison between the best ensemble member (blue dashed line in Figs. 5a,b) and the worst ensemble member (blue dotted line in Figs. 5a,b) reveals that the worst ensemble member has the strongest anomalous upward surface heat flux, together with about $+0.25 \mathrm{~mm} \mathrm{day}^{-1}$ precipitation anomalies over the WP during the transitioning La Niña summer, JJA-T (this is compared to NCEP-NCAR $\mathrm{R} 1$ with precipitation anomalies of about $-0.5 \mathrm{~mm} \mathrm{day}^{-1}$ ). On the contrary, the best ensemble member (blue dashed line in Figs. 5a,b) features only weak anomalous upward surface heat flux and the driest WP among the 16 ensemble members. The differences in the anomalous surface heat flux across the ensemble members are mainly caused by the differences in anomalous surface wind (not shown). Accordingly, the lack of air-sea interaction in CAM5-GOGA allows incorrect upward local surface heat flux anomalies which weaken the dry precipitation anomalies over the WP, resulting in a weaker/ incorrect tropical WP forcing in the model.

Incorrect air-sea coupling in a model may be more of a problem in the ENSO summer season than in the ENSO winter season. During the preceding El Niño winter, strong anomalous deep convection over the tropical $\mathrm{CP}$ dominates the 

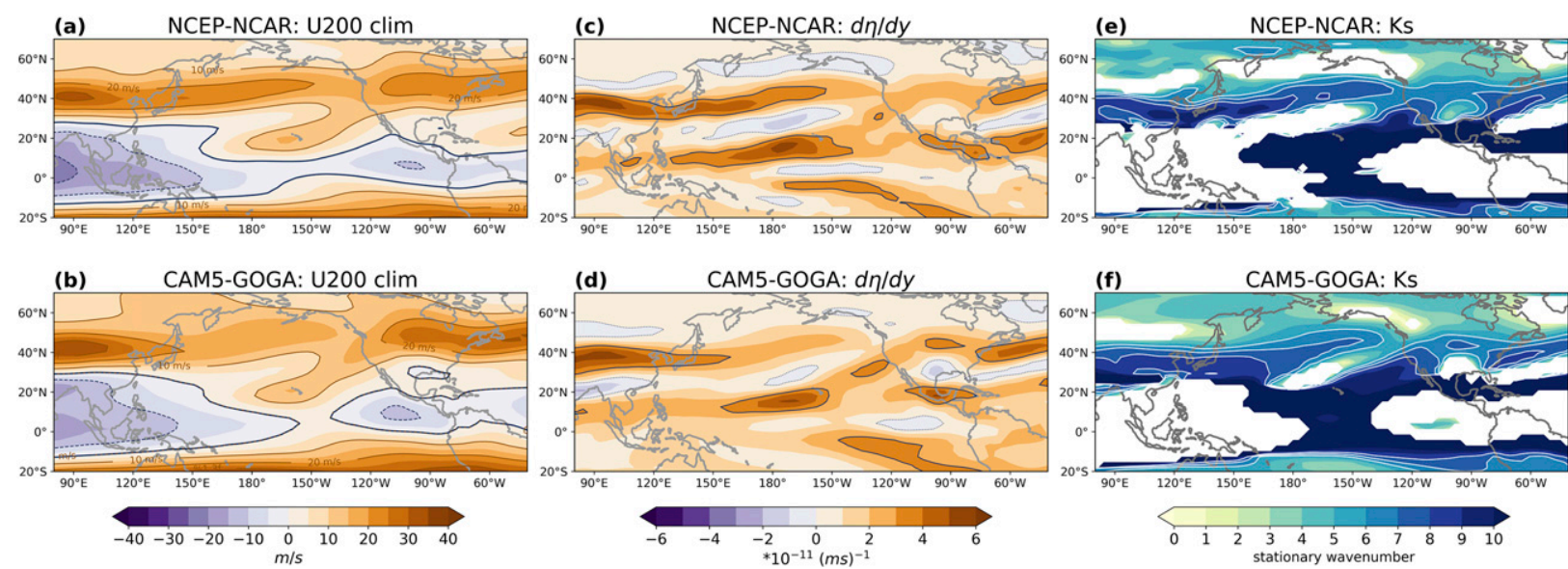

FIG. 6. (a),(b) Climatological JJA 3-month-averaged zonal wind at $200 \mathrm{hPa}$ (U200) from (a) NCEP-NCAR R1 and (b) CAM5-GOGA ensemble mean. Contours represent climatological values with interval of $10 \mathrm{~m} \mathrm{~s}^{-1}$. Thick solid lines indicate climatological $0 \mathrm{~m} \mathrm{~s}^{-1}$ isotach. (c),(d) The composites of JJA meridional gradient of absolute vorticity at $200 \mathrm{hPa}$ from (c) NCEP-NCAR R1 and (d) CAM5GOGA ensemble mean for the transitioning La Niña summers. Contours indicate $3 \times 10^{-11} \mathrm{~m}^{-1} \mathrm{~s}^{-1}$; gray dotted lines indicate $0 \mathrm{~m}^{-1} \mathrm{~s}{ }^{-1}$. (e),(f) Stationary wavenumber $\left(K_{s}\right)$ during the transitioning La Niña summers, derived from (a)-(d). Areas of easterly wind (U200 $\left.<0\right)$ and negative composites of $\beta_{\varphi}$ are in white. White contours indicate $K_{s}=6,7$, and 8 .

atmospheric anomalies across the tropical Pacific. Negative precipitation anomalies over the WP are well simulated in the model with good agreement across all the ensemble members (Fig. 5a), even though the local surface heat flux anomalies show a large spread and are much weaker than observed (Fig. 5b), and are probably a response to the enhanced precipitation in the equatorial CP. Thus, active air-sea interaction in climate models may be critical to reasonably simulate ENSO tropical forcing in the summer season when it is less dominated by the equatorial $\mathrm{CP}$ forcing.

\section{d. Extratropical teleconnections in response to tropical forcing}

Although the decency of simulated extratropical teleconnections is largely constrained by the adequacy of simulated WP precipitation anomalies in model, the extratropical teleconnections are also affected by Rossby wave propagation which depends on the subtropical jet-stream location and intensity. In many AGCMs, nevertheless, a weaker and poleward-shifted North Pacific summer jet, compared to observations, is a longstanding bias, to which CAM5-GOGA is no exception (Wang et al. 2017; Chang et al. 2019; Schubert et al. 2019). Figures $6 \mathrm{a}$ and $6 \mathrm{~b}$ compare the climatological JJA upper-level zonal wind from NCEP-NCAR R1 with CAM5GOGA. The $20 \mathrm{~m} \mathrm{~s}^{-1}$ isotach of upper-level zonal wind extends to $150^{\circ} \mathrm{W}$ in the observations, but only extends to $150^{\circ} \mathrm{E}$ in CAM5-GOGA. The bias in the jet stream leads to bias in the meridional absolute vorticity gradient which acts as a waveguide for Rossby wave propagation when the gradient is positive (e.g., Hoskins and Ambrizzi 1993). In the reanalysis, the Pacific waveguide extends across the North Pacific reaching North America during the transitioning La Niña summers (Fig. 6c), providing a pathway for Rossby waves, triggered by local forcing in the tropics or subtropics, to propagate across the PNA region. In CAM5-GOGA, during the transitioning
La Niña summers, on the other hand, the waveguide is much weaker and westward-limited compared to the reanalysis (Fig. 6d). These discrepancies in the Pacific mean state and the resulting waveguide might not only limit the ability of Rossby waves to propagate from the WP to North America, but also alter the zonal and meridional scales of Rossby waves in the model. Stationary wavenumber $K_{s}$ can be used to estimate the scales of stationary Rossby waves (Figs. 6e,f). We define $K_{s}$ as

$$
K_{s}=\left(\frac{\beta_{\varphi}}{\bar{u}}\right)^{1 / 2} a \cos \varphi
$$

where $\beta_{\varphi}$ is the meridional gradient of absolute vorticity during the transitioning La Niña summers, $\bar{u}$ is the climatological mean zonal wind, $a$ is the radius of Earth, and $\varphi$ is latitude (Hoskins and Ambrizzi 1993; Newman and Sardeshmukh 1998). In NCEP-NCAR R1, large values of $K_{s}(\geq 7)$ stretch across the North Pacific toward the west coast of North America and are concentrated in a narrow band. This suggests that Rossby waves can travel across the entire extratropical North Pacific with high wavenumbers and confined by wave refraction into a narrow meridional waveguide during the transitioning La Niña summers (Fig. 6e). In CAM5-GOGA, the band of large $K_{s}$ is present but weak and diffuse compared to the reanalysis (Fig. 6f), which implies that the incorrect mean state in the model might not only limit the Rossby wave propagation, but also introduce errors in the scales of Rossby waves. Furthermore, the weaker waveguide might be blamed partially for the weaker simulated extratropical responses over North America in the model, as a waveguide tends to enhance the amplitude of Rossby waves (e.g., Hoskins and Ambrizzi 1993; Ambrizzi et al. 1995).

In summary, in CAM5-GOGA, which is forced with prescribed historical SST anomalies, the extratropical responses over North America during the transitioning La Niña summers are weaker and less consistent across the events, compared to 
(a) Ensemble

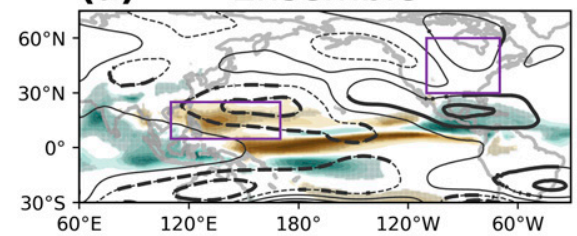

(c)

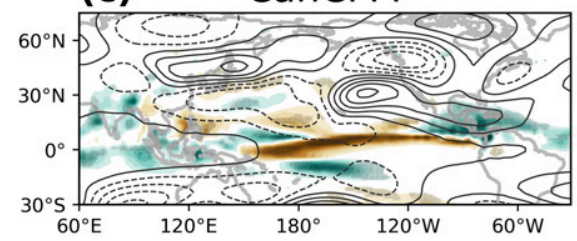

(e) NASA-GEOS5

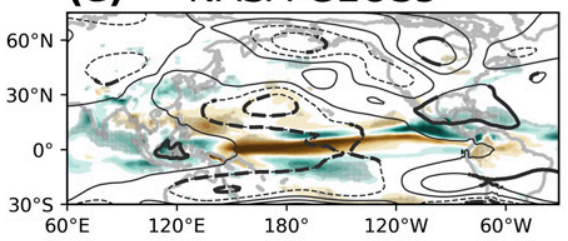

(g) GFDL-CM2.1

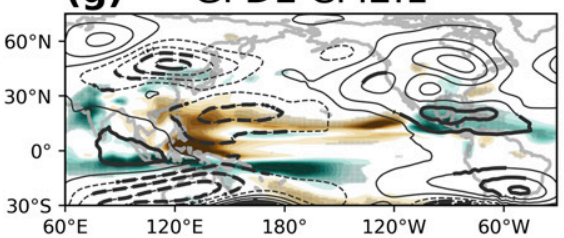

(b) NCEP-CFSV2

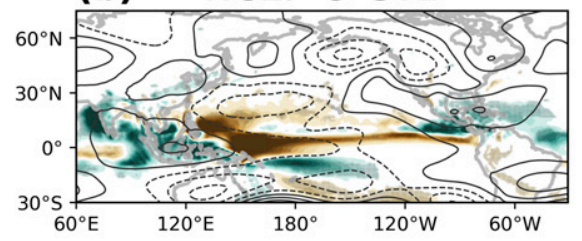

(d)

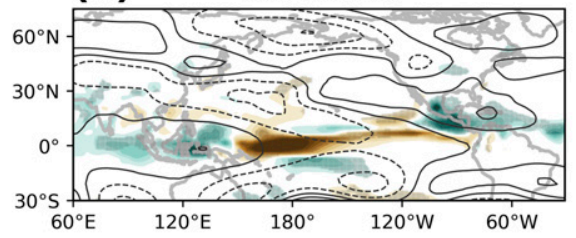

(f) GFDL-FLOR

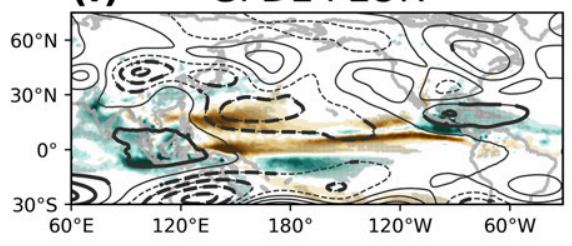

(h)

CCSM4

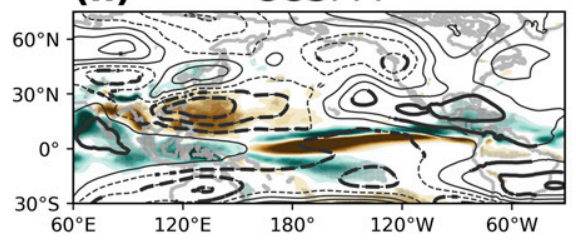

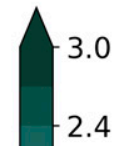

2.4

$-1.8$

$-1.2$

$-0.6$

-0.0 है

$-0.6$

$-1.2$

$-1.8$

$-2.4$

$-3.0$

FIG. 7. Composites of precipitation anomalies (shaded; $\mathrm{mm} \mathrm{day}^{-1}$ ) and 200-hPa geopotential height anomalies with the zonal mean removed (contours; interval: $5 \mathrm{~m}$ ) for the transitioning La Niña summers during 1982-2018 from (a) NMME multimodel ensemble mean and (b)-(h) the ensemble means of the individual models. Stippling denotes the $90 \%$ confidence for precipitation anomalies using a two-tailed Student's $t$ test. Thick lines indicate the $90 \%$ confidence for $200-\mathrm{hPa}$ height variations. Purple boxes indicate the subtropical WP and eastern North America regions used in Fig. 3.

observations. Inaccurate land-atmosphere processes in the model might compromise the simulated surface temperature responses, even when reasonable teleconnections are simulated. Nevertheless, in CAM5-GOGA, the performance of extratropical teleconnections is largely constrained by the unrealistically large variability in the precipitation anomalies over the subtropical WP, due to lack of active air-sea interactions. In light of this, we next examine the ENSO summer responses, in both the tropics and extratropics, in the NMME models in which air-sea coupling is present.

\section{NMME}

\section{a. Composites of tropical and extratropical responses in NMME}

We first consider the composites based on the multimodel ensemble mean across the seven NMME models (Figs. 7a and $8 \mathrm{a})$. In the tropics, the negative precipitation anomalies over the CP induced by the developing La Niña (Figs. 1a,c) are present in the NMME multimodel ensemble mean, although the anomalies tend to elongate zonally across the tropical Pacific (Fig. 7a). The negative precipitation anomalies over the subtropical WP, on the other hand, are more obvious and similar to NCEP-NCAR R1 than in the CAM5-GOGA ensemble mean (Fig. 2a). In spite of the more realistic diabatic heating forcing over the WP, the extratropical responses in the NMME multimodel ensemble mean share similar features to that in the CAM5-GOGA ensemble mean (Figs. 2a,d): with a weaker and statistically insignificant anomalous anticyclone over northeastern North America and only slightly warm Ts anomalies over the Midwest.

We further evaluate the performance of NMME, focusing on three key processes that connect the La Niña tropical SST anomalies to the U.S. surface temperature, as we did for CAM5-GOGA (Fig. 3).

\section{b. Processes that connect tropical forcing and extratropical responses}

The suppressed convection over the subtropical WP is triggered by the remote SST and modulated by local air-sea 

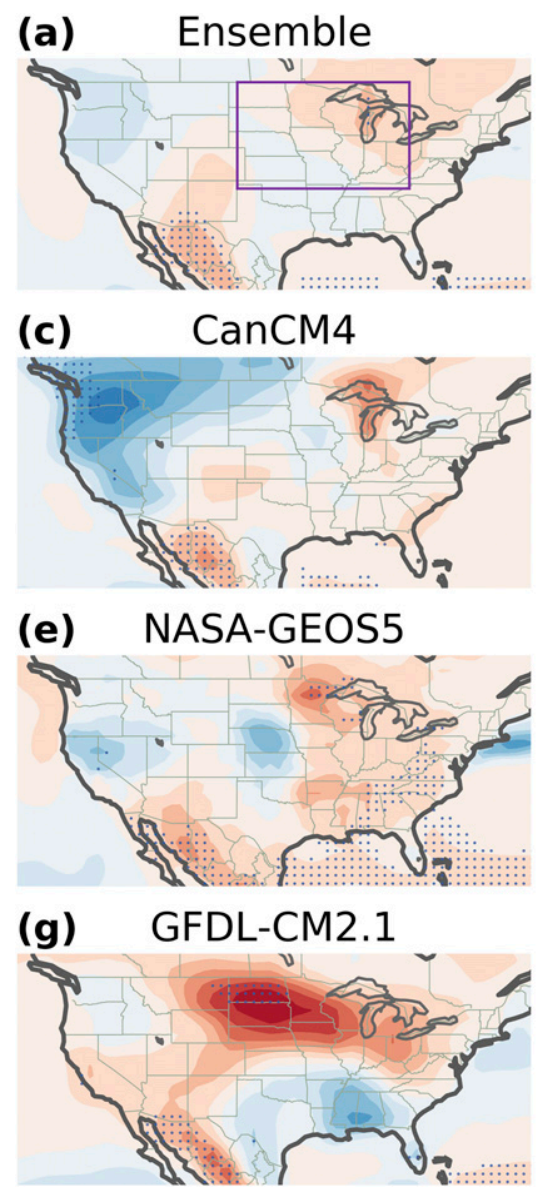
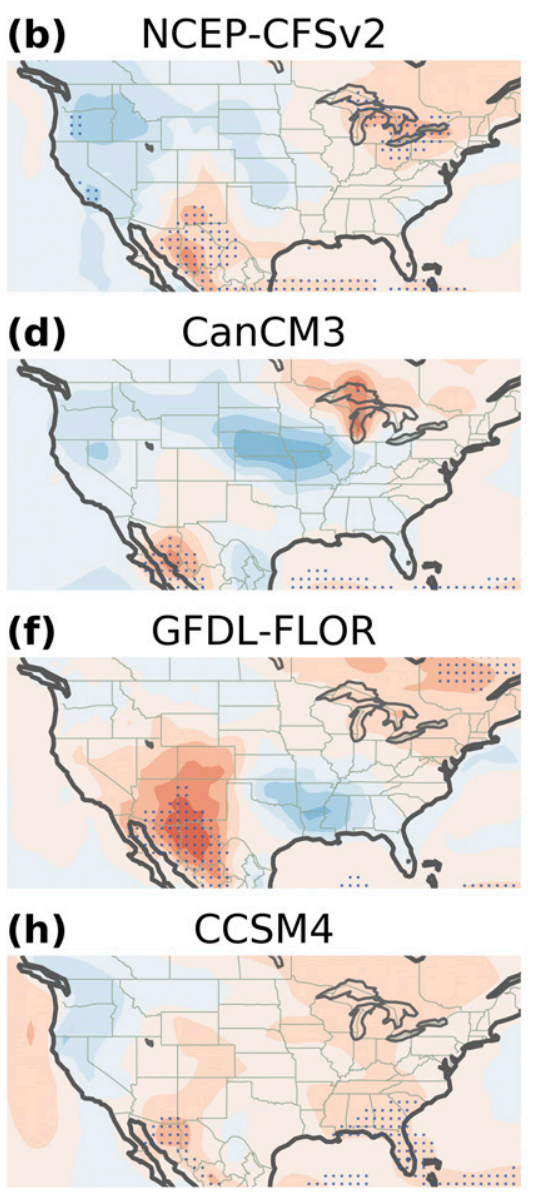

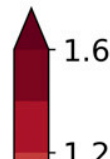

$-1.2$

$-0.8$

0.4

0.0
0.0
0

$-0.4$

$-0.8$

$-1.2$

FIG. 8. Composites of detrended Ts over the United States for the transitioning La Niña summers during 19822018 from (a) NMME multimodel ensemble mean and (b)-(h) the ensemble means of the individual models. Stippling denotes the $90 \%$ confidence for Ts anomalies using a two-tailed Student's $t$ test. The purple box indicates the Midwest region used in Fig. 3.

interaction. In the NMME models, the SST is forecast, which might lead to a different atmospheric response compared to specifying SSTs. In the observations (Fig. 3a), warm SST anomalies over the subtropical WP are a robust feature $(75 \%$ of the events during 1950-2018). In NMME, the ensemble means from individual models forecast slightly higher probability of warm SST anomalies than cold anomalies over the WP (Fig. 3c, right quadrants, orange dots, 64.2\%) for the historical transitioning La Niña summers during 1982-2018. Among these events with warm forecast WP SST anomalies, $69.5 \%$ $[44.6 \%$ out of $(44.6 \%+19.6 \%)]$ of them are also predicted to experience drier precipitation anomalies over the WP. Compared to CAM5-GOGA (Fig. 3b, orange dots), air-sea coupling brings the SST-precipitation relationship over the subtropical WP closer to observations.

Negative precipitation anomalies over the subtropical WP can contribute to the strength of the extratropical teleconnections over North America during the transitioning La Niña summer. For all the events from the individual model ensemble means, when negative precipitation anomalies are forecasted over the WP (Fig. 3f, lower quadrants, orange dots),
$63.6 \%$ [ $50 \%$ out of $(50 \%+28.6 \%)]$ of them have an anomalous anticyclone over North America. The multimodel ensemble mean of NMME (Fig. 3f, blue dots) exhibits a similar relationship between WP precipitation anomalies and anomalous circulation over E-NA to the observations (Fig. 3d): $75 \%$ of the events possess the negative WP precipitation-positive E-NA Z200 anomalies relationship. These results imply that when there is anomalous diabatic heating over the WP, the NMME models are capable of simulating the wave train propagation across the PNA region, augmenting the extratropical teleconnections triggered by the anomalous diabatic heating over the tropical CP.

On the other hand, the existence of an anomalous anticyclone over E-NA does not consistently lead to a warm anomaly of Ts over the Midwest during the transitioning La Niña summer, in disagreement with the observations (Fig. $3 g$ ). In the NMME models, there is a general positive relationship between the height anomalies over E-NA and surface temperature anomalies over the Midwest (Fig. 3i). However, among all the events from the individual model ensemble means (orange dots in Fig. 3i), when an anomalous anticyclone is forecast 
(right-upper and right-lower quadrants), only 58.3\% [37.5\% out of $(37.5 \%+26.8 \%)]$ of them have warming Ts over the Midwest. Among the events based on the NMME multimodel ensemble mean (blue dots in Fig. 3i), 66.7\% [50\% out of $(50 \%+25 \%)]$ of the events are forecast to have warm Ts over the Midwest with the presence of the anomalous anticyclone. These results suggest that with a correct forecast of the extratropical anticyclone over North America, the NMME models can forecast surface warming in the Midwest during the transitioning La Niña summer to some extent.

\section{c. Intermodel variability in tropical and extratropical responses}

In each component and relationship examined above, the performances vary considerably across the models. The negative precipitation anomalies over the subtropical WP, a robust feature in observations, show the most agreement across the models (Figs. 7b-h) with only the composite based on the CanCM3 failing to simulate the WP negative precipitation anomalies (Fig. 7d). The suppressed convection over the subtropical WP leads to an anomalous upper-level cyclone located to the northeast, a classic Gill-Matsuno response. The downstream wave train pattern, across the North Pacific to North America (anticyclone over the western-to-central North Pacific, cyclone over the Gulf of Alaska, and anticyclone over North America), is also present in most of the models' ensemble means. However, the exact locations and configurations of the wave trains vary with the models. The extratropical responses (contours in Figs. $7 b-h$ and $8 b-h$ ), therefore, exhibit large differences across the models, suggesting they have a wide range of skill in simulating the Rossby wave propagation across the PNA region. The Rossby wave propagation might be affected by the biases in the mean flow such as the subtropical jet.

Among these seven models, NASA-GEOS5 (Fig. 7e) has the most realistic anomalous atmospheric circulations: an anomalous anticyclone stretching northwest to southeast across the North Pacific, an anomalous cyclone over the Gulf of Alaska, and a statistically significant anomalous anticyclone over North America, the only model that predicts this feature. NASA-GEOS5 also simulates the statistically significant warm Ts anomalies over the Midwest (Fig. 8e). GFDL-CM2.1 exhibits a statistically significant warm anomaly over the northern Great Plains (Fig. 8g), located slightly west of the observed warm anomalies (Figs. 1b,d), but the extratropical teleconnections over North America in GFDL-CM2.1 are not statistically significant at the $90 \%$ confidence level (Fig. $7 \mathrm{~g}$ ).

In short, there exists a large intermodel variability in the extratropical responses among these seven NMME models, even with reasonable agreement in the simulated diabatic heating anomalies over the subtropical WP. This supports the idea that air-sea interaction is critical to simulate the precipitation anomalies over the WP during the transitioning La Niña summer. Yet, to model the correct ENSO summer teleconnections over extratropical North America, skillful representations of the Rossby wave propagation and land-atmosphere processes are also essential (e.g., Seager et al. 2020).

\section{Conclusions and discussion}

\section{a. Conclusions}

Here we have assessed the performance skill of climate models in terms of ENSO teleconnections and remote impacts on North America during developing La Niña summer (JuneAugust). Based on observations, during the summer when an El Niño event is transitioning to a La Niña event, the decaying El Niño and the developing La Niña trigger suppressed deep convection over the subtropical western Pacific (WP) and the tropical central Pacific (CP), respectively. Both regions of suppressed convection induce Rossby wave propagation across the Pacific-North America sector, resulting in a statistically significant anomalous anticyclone over eastern North America which leads to the robust warming over the Midwest. We have examined to what extent state-of-the-art climate models can simulate these prominent extratropical responses over North America during the transitioning La Niña summer, based on NCAR-CAM5 AGCM experiments (CAM5-GOGA) and NMME operational forecasting models.

In CAM5-GOGA and the NMME models, the model ensemble means, in general, are able to simulate the observed features in both the tropics (including the suppressed convection over the tropical CP and subtropical WP) and the extratropics (the anomalous anticyclone over eastern North America and the warm Ts anomalies over the Midwest) during the transitioning La Niña summer. However, the extratropical responses in these models' ensemble means are much weaker and less significant, compared to NCEP-NCAR R1.

To address the weak SST-forced signals over the extratropics in these climate models, we have anatomized the physical processes that connect the tropical forcing to extratropical North America into three parts:

1) The suppressed convection over the subtropical WP plays an important role in strengthening the extratropical teleconnections during the transitioning La Niña summer. The negative precipitation anomalies over the WP are the results of remote SST forcing over the Indian Ocean and local air-sea interaction. Therefore, in the CAM5-GOGA ensemble mean, with air-sea interaction disabled, the simulated negative precipitation anomalies over the WP are weaker and have much larger variability across the historical events, compared to observations. Coupled models, such as NMME, in which SSTs are determined by coupled ocean-atmosphere processes, are able to simulate the combination of warm SST anomalies and reduced precipitation over the WP, consistent with observations.

2) How well the models simulate the extratropical circulations is linked to how well they simulate the WP precipitation anomalies. In CAM5-GOGA, the ensemble members that best simulate the extratropical teleconnections are those that best simulate negative WP precipitation anomalies during the transitioning La Niña summers. In most of the NMME models, reduced WP precipitation coexists with an anomalous anticyclone over eastern North America. Nevertheless, the modeled relationship between reduced WP precipitation and the anomalous anticyclone over eastern North America is less consistent across events than 
in the observations and the amplitudes of the modeled extratropical teleconnections are too weak. Weaker and less consistent Rossby wave propagations might be partially attributed to the weaker North Pacific jet stream, a longstanding model bias, and the resulting weaker Rossby waveguide.

3) Also, in the climate models, reasonable extratropical teleconnections do not guarantee surface warming over the Midwest during the transitioning La Niña summer. In observations, the strong surface warming over the Midwest is a robust feature associated with the anomalous anticyclone. However, in both CAM5-GOGA and the NMME models, an anomalous anticyclone does not translate into anomalous warming over the Midwest during the transitioning La Niña summers. The incorrect relationship between anomalous circulation and surface temperature possibly indicates issues associated with the representations of landatmosphere processes in the models

On the whole, climate models have limited skill in capturing the robust observed warming anomalies over the Midwest during the transitioning La Niña summers. Even with the reasonable presence of ENSO tropical forcing in the models, the downstream wave train pattern and the resulting extratropical responses over North America exhibit large disagreement across the models and are consistently weaker than in observations. These results suggest that biases regarding the representations of Rossby wave propagation and landatmosphere processes in the climate models may limit their skill in predicting summertime extratropical atmospheric circulations and hydroclimate variability over North America.

\section{b. Discussion}

There have been several longstanding biases in the summer season in many generations of climate models. As the robust warming anomalies over the Midwest are linked to reduced crop yields in the United States (Anderson et al. 2017a), it is worth discussing the possible connections between these model biases and the inability of models to capture the Midwest warming signal during transitioning La Niña summers.

A strong warm bias in the summertime surface temperature over the central United States including the Midwest is one of the longstanding biases of climate models (e.g., Mueller and Seneviratne 2014; Merrifield and Xie 2016; Lin et al. 2017; Morcrette et al. 2018). The potential causes of the warm bias include inability to simulate strong rainfall events caused by mesoscale convective systems over the central United States, underestimation of shallow cumulus clouds and misrepresentation of soil moisture (Lin et al. 2017). On top of these errors, current climate models generally overestimate the strength of land-atmosphere coupling (e.g., Merrifield and Xie 2016). These model deficiencies regarding land-atmosphere processes over North America could constrain their ability to simulate the robust warm Ts anomalies over the Midwest during the transitioning La Niña summer. However, more comprehensive work is required to carefully investigate the possible contribution of these biases regarding land-atmosphere processes to the incorrect connection between the anticyclone and surface warming over the Midwest in the climate models.
In addition to local errors in climate models, remote errors such as the unrealistically weak subtropical jet stream can considerably limit the predictive ability of the extratropical responses in these models (e.g., Wang et al. 2017; O'Reilly et al. 2018). Recent studies have shown that, using NASA-GEOS AGCM as an example, the biased subtropical jet stream causes simulated Rossby wave propagation to reach North America with incorrect speed and direction, and deteriorates summertime $2 \mathrm{~m}$ air temperature forecasts over North America (Wang et al. 2017; Chang et al. 2019; Schubert et al. 2019). This conspicuous error in the basic state and its downstream impacts on North America demonstrate the challenge of current climate models to skillfully predict Northern Hemisphere extratropical atmospheric circulations and hydroclimate variability over North America during the summer season.

In the NMME models, although the models show a reasonable agreement in the negative WP precipitation anomalies across the models and with observations, the extratropical teleconnections exhibit a large disagreement across the models and are consistently weaker than in observations. Beside the biases in the subtropical jet stream and land-atmosphere processes, the erroneous precipitation anomalies over the tropical CP might be another potential source of errors. In all the NMME models, the negative precipitation anomalies over the tropical $\mathrm{CP}$, induced by the developing La Niña, are unrealistically zonally elongated (Fig. 7), which is possibly related to the westward bias in ENSO-related tropical SST anomalies in the NMME models (e.g., Newman and Sardeshmukh 2017). The incorrect spatial extent of the suppressed convection over the tropical CP might partly contribute to the weaker extratropical responses over North America compared to observations. Also, the maximums of the suppressed convection are located at various longitudes and latitudes across the models, which could lead to the different performances of the extratropical teleconnections across the models. This raises the importance of further examining to what extent the westward bias in ENSO tropical SST anomalies in the NMME models affects the seasonal forecasts of extratropical responses over North America during the ENSO summer season.

Climate models' ability to simulate intraseasonal variability could also contribute to the errors in simulating extratropical teleconnections in the ENSO summer. For example, current climate models have limited skill in simulating intraseasonal precipitation variability in the warm season, especially over the Indo-WP region (e.g., Kim et al. 2011; Vitart 2017; Moron et al. 2019), which would further introduce errors in downstream Rossby wave propagation. Also, the subtropical jet stream in the North Pacific weakens and shifts poleward from June to August (Newman and Sardeshmukh 1998). This shift in the basic state could modulate the teleconnections patterns that connect remote forcing and impacts over North America on the subseasonal time scale (e.g., Chen and Newman 1998; Castro et al. 2007). As intraseasonal variability could impose loading on the 3-month average to some extent, the fidelity of climate models in simulating intraseasonal variability of tropical precipitation and shift in the subtropical jet stream might constrain the seasonal forecasting skill during ENSO summer.

To summarize, in climate models, how well the extratropical responses to ENSO tropical forcing in summers transitioning 
from El Niño to La Niña are modeled is determined, at least, by the models' skills in simulating air-sea interaction, tropical forcing (anomalous convective activities), Rossby wave propagation, and, potentially, land-atmosphere interaction. During summer, the weak subtropical jet stream and strong landatmosphere coupling are likely sources of bias. Improving forecast models requires further addressing:

- Why are the NMME models not skillful at forecasting the warm SST anomalies over the subtropical WP (Fig. 3c) and the suppressed convection over the tropical CP (Fig. 7) during the transitioning La Niña summer?

- To what extent does the weaker and westward-limited subtropical jet stream in the models affect Rossby wave propagations during the ENSO transitioning summer season?

- Why do the models not correctly connect anomalous anticyclones with surface temperature warming? Are biases in land-atmosphere interactions responsible?

This study hopefully points the way forward to efforts to improve tropical SST-based model forecasting skill of North American summer hydroclimate variability.

Acknowledgments. This study was supported by NOAA NA17OAR4310126 and NSF OCE 1657209. Bor-Ting Jong was also funded by National Research Council (NRC) Research Associateship Programs. We are grateful to Jason Smerdon, Arun Kumar, Andrew Robertson, Matthew Newman, and Shang-Ping Xie for comments on various aspects of this research. We also thank Donna Lee for performing the CAM5-GOGA simulations used in this research. We also acknowledge three anonymous reviewers for their constructive comments.

\section{REFERENCES}

Ambrizzi, T., B. J. Hoskins, and H.-H. Hsu, 1995: Rossby wave propagation and teleconnection patterns in the austral winter. J. Atmos. Sci., 52, 3661-3672, https://doi.org/10.1175/15200469(1995)052<3661:RWPATP>2.0.CO;2.

Anderson, W., R. Seager, W. Baethgen, and M. Cane, 2017a: Life cycles of agriculturally relevant ENSO teleconnections in North and South America. Int. J. Climatol., 37, 3297-3318, https://doi.org/10.1002/joc.4916.

,,--- , and,$- 2017 \mathrm{~b}$ : Crop production variability in North and South America forced by life-cycles of the El NiñoSouthern Oscillation. Agric. For. Meteor., 239, 151-165, https://doi.org/10.1016/j.agrformet.2017.03.008.

Branstator, G., 2002: Circumglobal teleconnections, the jet stream waveguide, and the North Atlantic Oscillation. J. Climate, 15, 1893-1910, https://doi.org/10.1175/1520-0442(2002)015<1893: CTTJSW $>2.0 . \mathrm{CO} ; 2$.

Castro, C. L., R. A. Pielke, J. O. Adegoke, S. D. Schubert, and P. J. Pegion, 2007: Investigation of the summer climate of the contiguous United States and Mexico using the Regional Atmospheric Modeling System (RAMS). Part II: Model climate variability. J. Climate, 20, 3866-3887, https://doi.org/10.1175/JCLI4212.1.

Chang, Y., S. D. Schubert, R. D. Koster, A. M. Molod, and H. Wang, 2019: Tendency bias correction in coupled and uncoupled global climate models with a focus on impacts over North America. J. Climate, 32, 639-661, https://doi.org/ 10.1175/JCLI-D-18-0598.1.
Chen, P., and M. Newman, 1998: Rossby wave propagation and the rapid development of upper-level anomalous anticyclones during the 1988 U.S. drought. J. Climate, 11, 2491-2504, https://doi.org/ 10.1175/1520-0442(1998)011<2491:RWPATR >2.0.CO;2.

Danabasoglu, G., S. C. Bates, B. P. Briegleb, S. R. Jayne, M. Jochum, W. G. Large, S. Peacock, and S. G. Yeager, 2012: The CCSM4 ocean component. J. Climate, 25, 1361-1389, https://doi.org/10.1175/JCLI-D-11-00091.1.

Dee, D. P., and Coauthors, 2011: The ERA-interim reanalysis: Configuration and performance of the data assimilation system. Quart. J. Roy. Meteor. Soc., 137, 553-597, https://doi.org/ 10.1002/qj.828.

Delworth, T. L., and Coauthors, 2006: GFDL's CM2 global coupled climate models. Part I: Formulation and simulation characteristics. J. Climate, 19, 643-674, https://doi.org/10.1175/ JCLI3629.1.

Ding, Q., and B. Wang, 2005: Circumglobal teleconnection in the Northern Hemisphere summer. J. Climate, 18, 3483-3505, https://doi.org/10.1175/JCLI3473.1.

,,-- J. M. Wallace, and G. Branstator, 2011: Tropicalextratropical teleconnections in boreal summer: Observed interannual variability. J. Climate, 24, 1878-1896, https:// doi.org/10.1175/2011JCLI3621.1.

Fang, S. W., and J. Y. Yu, 2020: A control of ENSO transition complexity by tropical Pacific mean SSTs through tropical-subtropical interaction. Geophys. Res. Lett., 47, e2020GL087933, https://doi.org/ 10.1029/2020GL087933.

Guo, Y., M. Ting, Z. Wen, and D. Eun Lee, 2017: Distinct patterns of tropical Pacific SST anomaly and their impacts on North American climate. J. Climate, 30, 5221-5241, https://doi.org/ 10.1175/JCLI-D-16-0488.1.

Hoskins, B. J., and D. Karoly, 1981: The steady linear response of a spherical atmosphere to thermal and orographic forcing. J. Atmos. Sci., 38, 1179-1196, https://doi.org/10.1175/15200469(1981)038<1179:TSLROA > 2.0.CO;2.

— longitudinally varying flow. J. Atmos. Sci, 50, 1661-1671, https:// doi.org/10.1175/1520-0469(1993)050<1661:RWPOAR>2.0.CO;2.

Hu, Z. Z., A. Kumar, Y. Xue, and B. Jha, 2014: Why were some La Niñas followed by another La Niña? Climate Dyn., 42, 10291042, https://doi.org/10.1007/s00382-013-1917-3.

Jong, B.-T., M. Ting, R. Seager, and W. B. Anderson, 2020: ENSO teleconnections and impacts on U.S. summertime temperature during a multiyear La Niña life cycle. J. Climate, 33, 60096024, https://doi.org/10.1175/JCLI-D-19-0701.1.

Kalnay, E., and Coauthors, 1996: The NCEP/NCAR 40-Year Reanalysis Project. Bull. Amer. Meteor. Soc., 77, 437-471, https://doi.org/ 10.1175/1520-0477(1996)077<0437:TNYRP >2.0.CO;2.

Kim, D., A. H. Sobel, E. D. Maloney, D. M. W. Frierson, and I. S. Kang, 2011: A systematic relationship between intraseasonal variability and mean state bias in AGCM simulations. J. Climate, 24, 55065520, https://doi.org/10.1175/2011JCLI4177.1.

Kirtman, B. P., and Coauthors, 2014: The North American Multimodel Ensemble: Phase-1 seasonal-to-interannual prediction; phase-2 toward developing intraseasonal prediction. Bull. Amer. Meteor. Soc., 95, 585-601, https://doi.org/10.1175/ BAMS-D-12-00050.1.

Kobayashi, S., and Coauthors, 2015: The JRA-55 reanalysis: General specifications and basic characteristics. J. Meteor. Soc. Japan, 93, 5-48, https://doi.org/10.2151/jmsj.2015-001.

Larkin, N. K., and D. E. Harrison, 2002: ENSO warm (El Niño) and cold (La Niña) event life cycles: Ocean surface anomaly patterns, their symmetries, asymmetries, and implications. 
J. Climate, 15, 1118-1140, https://doi.org/10.1175/1520-0442(2002) 015<1118:EWENOA > 2.0.CO;2.

Lau, N.-C., A. Leetmaa, M. J. Nath, and H.-L. Wang, 2005: Influences of ENSO-induced Indo-Western Pacific SST anomalies on extratropical atmospheric variability during the boreal summer. J. Climate, 18, 2922-2942, https://doi.org/ 10.1175/JCLI3445.1.

Lee, D. E., M. Ting, N. Vigaud, Y. Kushnir, and A. G. Barnston, 2018: Atlantic multidecadal variability as a modulator of precipitation variability in the Southwest United States. J. Climate, 31, 5525-5542, https://doi.org/10.1175/JCLI-D-170372.1.

Liang, Y.-C., J.-Y. Yu, M.-H. Lo, and C. Wang, 2015: The changing influence of El Niño on the Great Plains low-level jet. Atmos. Sci. Lett., 16, 512-517, https://doi.org/10.1002/asl.590.

Lin, Y., W. Dong, M. Zhang, Y. Xie, W. Xue, J. Huang, and Y. Luo, 2017: Causes of model dry and warm bias over central U.S. and impact on climate projections. Nat. Commun., 8, 881, https:// doi.org/10.1038/s41467-017-01040-2.

Liu, A. Z., M. Ting, and H. Wang, 1998: Maintenance of circulation anomalies during the 1988 drought and 1993 floods over the United States. J. Atmos. Sci., 55, 2810-2832, https://doi.org/ 10.1175/1520-0469(1998)055<2810:MOCADT>2.0.CO;2.

Livneh, B., and M. P. Hoerling, 2016: The physics of drought in the U.S. Central Great Plains. J. Climate, 29, 6783-6804, https:// doi.org/10.1175/JCLI-D-15-0697.1.

Lopez, H., S. K. Lee, S. Dong, G. Goni, B. Kirtman, R. Atlas, and A. Kumar, 2019: East Asian monsoon as a modulator of U.S. Great Plains heat waves. J. Geophys. Res. Atmos., 124, 63426358, https://doi.org/10.1029/2018JD030151.

Malloy, K. M., and B. P. Kirtman, 2020: Predictability of midsummer Great Plains low-level jet and associated precipitation. Wea. Forecasting, 35, 215-235, https://doi.org/10.1175/ WAF-D-19-0103.1.

McPhaden, M. J., and X. Zhang, 2009: Asymmetry in zonal phase propagation of ENSO sea surface temperature anomalies. Geophys. Res. Lett., 36, L13703, https://doi.org/10.1029/ 2009GL038774.

Meehl, G. A., and C. Tebaldi, 2004: More intense, more frequent, and longer lasting heat waves in the 21st century. Science, $\mathbf{3 0 5}$, 994-997, https://doi.org/10.1126/science.1098704.

Merrifield, A. L., and S.-P. Xie, 2016: Summer U.S. surface air temperature variability: Controlling factors and AMIP simulation biases. J. Climate, 29, 5123-5139, https://doi.org/ 10.1175/JCLI-D-15-0705.1.

Merryfield, W. J., and Coauthors, 2013: The Canadian Seasonal to Interannual Prediction System. Part I: Models and initialization. Mon. Wea. Rev., 141, 2910-2945, https://doi.org/10.1175/ MWR-D-12-00216.1.

Morcrette, C. J., and Coauthors, 2018: Introduction to CAUSES: Description of weather and climate models and their nearsurface temperature errors in 5 day hindcasts near the Southern Great Plains. J. Geophys. Res. Atmos., 123, 26552683, https://doi.org/10.1002/2017JD027199.

Moron, V., A. W. Robertson, and L. Wang, 2019: Weather within climate: Sub-seasonal predictability of tropical daily rainfall characteristics. Sub-Seasonal to Seasonal Prediction: The Gap between Weather and Climate Forecasting, A. Robertson and F. Vitart, Eds., Elsevier, 47-65.

Mueller, B., and S. I. Seneviratne, 2014: Systematic land climate and evapotranspiration biases in CMIP5 simulations. Geophys. Res. Lett., 41, 128-134, https://doi.org/10.1002/ 2013GL058055.
Neale, R. B., and Coauthors, 2012: Description of the NCAR Community Atmosphere Model (CAM 5.0). NCAR Tech. Note NCAR/TN-486+STR, 289 pp., www.cesm.ucar.edu/ models/cesm1.0/cam/docs/description/cam5_desc.pdf.

Newman, M., and P. D. Sardeshmukh, 1998: The impact of the annual cycle on the North Pacific/North American response to remote lowfrequency forcing. J. Atmos. Sci., 55, 1336-1353, https://doi.org/ 10.1175/1520-0469(1998)055<1336:TIOTAC $>2.0$. CO; 2 .

— ical Indo-Pacific sea surface temperatures? Geophys. Res. Lett., 44, 8520-8529, https://doi.org/10.1002/2017GL074088.

Okumura, Y. M., 2019: ENSO diversity from an atmospheric perspective. Curr. Climate Change Rep., 5, 245-257, https:// doi.org/10.1007/s40641-019-00138-7.

O'Reilly, C. H., T. Woollings, L. Zanna, and A. Weisheimer, 2018: The impact of tropical precipitation on summertime EuroAtlantic circulation via a circumglobal wave train. J. Climate, 31, 6481-6504, https://doi.org/10.1175/JCLI-D-17-0451.1.

Rasmusson, E., and T. Carpenter, 1982: Variations in tropical sea surface temperature and surface wind fields associated with the Southern Oscillation/El Niño. Mon. Wea. Rev., 110, 354-384, https://doi.org/ 10.1175/1520-0493(1982)110<0354:VITSST >2.0.CO;2.

Saha, S., and Coauthors, 2006: The NCEP Climate Forecast System. J. Climate, 19, 3483-3517, https://doi.org/10.1175/ JCLI3812.1.

- , and Coauthors, 2014: The NCEP Climate Forecast System version 2. J. Climate, 27, 2185-2208, https://doi.org/10.1175/ JCLI-D-12-00823.1.

Schubert, S. D., H. Wang, and M. Suarez, 2011: Warm season subseasonal variability and climate extremes in the Northern Hemisphere: The role of stationary Rossby waves. J. Climate, 24, 4773-4792, https://doi.org/10.1175/JCLI-D-10-05035.1.

—_, Y. Chang, H. Wang, R. D. Koster, and A. M. Molod, 2019: A systematic approach to assessing the sources and global impacts of errors in climate models. J. Climate, 32, 8301-8321, https://doi.org/10.1175/JCLI-D-19-0189.1.

Seager, R., J. Nakamura, and M. Ting, 2020: Prediction of seasonal meteorological drought onset and termination over the southern Great Plains in the North American Multimodel Ensemble. J. Hydrometeor., 21, 2237-2255, https://doi.org/ 10.1175/JHM-D-20-0023.1.

Teng, H., G. Branstator, H. Wang, G. A. Meehl, and W. M. Washington, 2013: Probability of U.S. heat waves affected by a subseasonal planetary wave pattern. Nat. Geosci., 6, 10561061, https://doi.org/10.1038/ngeo1988.

Ting, M., and P. D. Sardeshmukh, 1993: Factors determining the extratropical response to equatorial diabatic heating anomalies. J. Atmos. Sci., 50, 907-918, https://doi.org/10.1175/15200469(1993)050<0907:FDTERT>2.0.CO;2.

— ability and its relation to Pacific sea surface temperature. J. Climate, 10, 1853-1873, https://doi.org/10.1175/15200442(1997)010<1853:SUSPVA>2.0.CO;2.

Titchner, H. A., and N. A. Rayner, 2014: The Met Office Hadley Centre sea ice and sea surface temperature data set, version 2: 1. Sea ice concentrations. J. Geophys. Res. Atmos., 119, 28642889, https://doi.org/10.1002/2013JD020316.

Trenberth, K. E., and D. J. Shea, 2005: Relationships between precipitation and surface temperature. Geophys. Res. Lett., 32, L14703, https://doi.org/10.1029/2005GL022760.

Vecchi, G. A., and Coauthors, 2014: On the seasonal forecasting of regional tropical cyclone activity. J. Climate, 27, 7994-8016, https://doi.org/10.1175/JCLI-D-14-00158.1. 
Vernieres, G., M. Rienecker, R. Kovach, and C. L. Keppenne, 2012: The GEOS-iODAS: Description and evaluation. Technical Report Series on Global Modeling and Data Assimilation, M. J. Suarez, Ed., Vol. 30, NASA Tech Memo. NASA/TM-2012-104606, 73 pp., https:/gmao.gsfc.nasa.gov/ pubs/docs/Vernieres589.pdf.

Vitart, F., 2017: Madden-Julian Oscillation prediction and teleconnections in the S2S database. Quart. J. Roy. Meteor. Soc., 143, 2210-2220, https://doi.org/10.1002/qj.3079.

Wang, B., R. Wu, and K.-M. Lau, 2001: Interannual variability of the Asian summer monsoon: Contrasts between the Indian and the western North Pacific-East Asian monsoons. J. Climate, 14, 4073-4090, https://doi.org/10.1175/1520-0442(2001)014<4073: IVOTAS $>2.0 . \mathrm{CO} ; 2$.

—_, and Coauthors, 2009: Advance and prospectus of seasonal prediction: Assessment of the APCC/CliPAS 14-model ensemble retrospective seasonal prediction (1980-2004). Climate Dyn., 33, 93-117, https://doi.org/10.1007/s00382-008-0460-0.

Wang, H., S. D. Schubert, and R. D. Koster, 2017: North American drought and links to northern Eurasia: The role of stationary Rossby waves. Climate Extremes: Patterns and Mechanisms, S.-Y. S. Wang et al., Eds., Amer. Geophys. Union, 195-221.

Wang, Z., C.-P. Chang, and B. Wang, 2007: Impacts of El Niño and La Niña on the U.S. climate during northern summer. J. Climate, 20, 2165-2177, https://doi.org/10.1175/JCLI4118.1.

Weaver, S. J., and S. Nigam, 2008: Variability of the Great Plains low-level jet: Large-scale circulation context and hydroclimate impacts. J. Climate, 21, 1532-1551, https://doi.org/10.1175/ 2007JCLI1586.1.
Wu, R., and B. P. Kirtman, 2007: Regimes of seasonal air-sea interaction and implications for performance of forced simulations. Climate Dyn., 29, 393-410, https://doi.org/10.1007/ s00382-007-0246-9.

Wu, X., Y. M. Okumura, and P. N. Dinezio, 2019: What controls the duration of El Niño and La Niña events? J. Climate, 32, 5941-5965, https://doi.org/10.1175/JCLI-D-18-0681.1.

Xie, S.-P., K. Hu, J. Hafner, H. Tokinaga, Y. Du, G. Huang, and T. Sampe, 2009: Indian Ocean capacitor effect on Indo-western Pacific climate during the summer following El Niño. J. Climate, 22, 730-747, https://doi.org/10.1175/2008JCLI2544.1.

_- Y. Kosaka, Y. Du, and K. M. Hu, 2016: Indo-western Pacific Ocean capacitor and coherent climate anomalies in postENSO summer: A review. Adv. Atmos. Sci., 33, 411-432, https://doi.org/10.1007/s00376-015-5192-6.

Yan, Y., and Coauthors, 2020: Climatology and interannual variability of floods during the TRMM era (1998-2013). J. Climate, 33, 3289-3305, https://doi.org/10.1175/JCLI-D-19-0415.1.

Yu, J. Y., and S. W. Fang, 2018: The distinct contributions of the seasonal footprinting and charged-discharged mechanisms to ENSO complexity. Geophys. Res. Lett., 45, 6611-6618, https:// doi.org/10.1029/2018GL077664.

Zhou, Z. Q., S. P. Xie, G. J. Zhang, and W. Zhou, 2018: Evaluating AMIP skill in simulating interannual variability over the Indo-western Pacific. J. Climate, 31, 2253-2265, https:// doi.org/10.1175/JCLI-D-17-0123.1.

Zhu, Z., and T. Li, 2016: A new paradigm for continental U.S. summer rainfall variability: Asia-North America teleconnection. J. Climate, 29, 7313-7327, https://doi.org/10.1175/JCLID-16-0137.1. 
